\title{
MARÍA CRISTINA DE BORBÓN-DOS SICILIAS Y SUS VÍNCULOS CON POLONIA Y LOS POLACOS
}

\author{
Barbara Obtułowicz \\ Universidad Pedagógica de Cracovia, Polonía \\ basiaobt@interia.pl
}

RESUMEN: La Reina María Cristina de Borbón-Dos Sicilias, duquesa de Riánsares, es un personaje que posee su "leyenda negra". Varios historiadores no quieren ver que la misma María Cristina, que en el campo político y económico cometió muchos errores y deshonestidades, en su vida privada era un ejemplo a seguir. Pocos de los conocedores del tema se han fijado en que ese "lado humano" lo supo mostrar también a los polacos. El objetivo del presente artículo es llenar esos huecos. A base de los manuscritos encontrados en los archivos españoles y polacos, se revela ante el lector el hilo desconocido de la relación de María Cristina y su segundo marido con Polonia y los polacos.

Palabras clave: María Cristina de Borbón-Dos Sicilias, Agustín Fernando Muñoz, duque de Riánsares, María Amparo Muñoz y de Borbón, princesa Czartoryski, familia de los príncipes Czartoryski, Polonia, polacos.

\section{MARÍA CRISTINA DE BORDÓN-DOS SICILIAS AND ITS RELATION WITH POLAND AND THE POLES}

\begin{abstract}
The Queen Maria Cristina of Bourbon-Two Sicilies, Duchess of Riánsares, is a character that is covered by its "black legend". Several historical has not wanted to see that María Cristina, who in the political and economic fields made many mistakes and improprieties, in his private life was an example to follow. Few specialists of the subject have noticed that the "human side" of her was to the Poles. The aim of this paper is to fill those gaps. Basing on the manuscripts found in the Spanish and Polish archives, the text tends to reveal an unknown relationship of María Cristina and her second husband with Poland and Poles.
\end{abstract}


Keywords: María Cristina de Borbón, Agustín Fernando Muñoz, duke of Riánsares, María Amparo Muñoz y de Bourbon, Princess Czartoryski, family of the Princes Czartoryski, Poland, poles.

Recibido: 16 de Febrero de 2016

Aceptado: 8 de Abril de 2016

La reina María Cristina de Borbón-Dos Sicilias es un personaje en torno a cual se ha creado una "leyenda negra". Basta mencionar que hasta la fecha no se le ha dedicado ninguna biografía. En cambio, sí se ha descrito la vida de su hija mayor, la reina Isabel II, que solo en los últimos años se ha convertido en protagonista de algunas extensas monografías. En España María Cristina de Borbón tiene mala opinión hasta tal punto que la animadversión hacia ella puede ser comparada a la que acompaña a María Luisa de Parma, la mujer de Carlos IV. No sin razón se le reprocha el ansia del poder, la codicia, se le acusa de haberse involucrado en varios negocios turbios y se le reprocha el descuido de sus hijas del primer matrimonio con Fernando VII (Isabel II y Luisa Fernanda). Cabe recordar que las causas de esa actitud se originan cuando contrajo su segundo matrimonio con el guardia Augustín Fernando Muñoz (desde el 1844. Duque de Riánsares), con quien tuvo ocho hijos. Era un matrimonio morganático y, además, en contra de la razón de Estado español, con lo cual los descendientes de los Muñoz no heredaron el título de los infantes ni tenían derecho a las propiedades pertenecientes a la Corona. Dada la situación, Ios propios padres tenían que hacerse cargo del mantenimiento de sus hijos. Asumiendo que en las venas de sus hijos fluía la sangre de la casa real, los Borbones vacilaron ante la tentación de abusar de la ley y honestidad con el propósito de asegurar su bienestar.

Pocos historiadores anotan que María Cristina (duquesa de Riánsares), que en el campo político y económico cometió muchos errores y deshonestidades, en su vida privada era un ejemplo a seguir. Cumplía con devoción con el papel de esposa, tanto cuando estaba casada con Fernando VII, al que cuidaba personalmente, como en su segundo matrimonio con Muñoz. Era una tierna madre para sus hijos y abuela para sus nietos ${ }^{1}$. Sin embargo, ninguno de los conocedores del tema se ha fijado en que el "lado humano" lo demostró también hacia los polacos. El objetivo del presente texto es rellenar este hueco. A base de los manuscritos, procedentes del Archivo Histórico Nacional en Madrid y la Biblioteca de los Príncipes Czartoryski en Cracovia, revelamos ante los lectores el

1. P. de Luz, Isabel II, Reina de España, Juventud, Barcelona 1943, p. 109. 
aspecto desconocido de esa relación de María Cristina y su segundo esposo² con Polonia y los polacos.

María Cristina, por los puestos que ocupaba, las funciones y las actividades que desempeñaba en los negocios, mantenía relaciones con los representantes de diferentes nacionalidades. Entre ellos se encontraban los polacos, miembros de una nación que a finales del siglo XVIII había perdido su soberanía y fue borrada del mapa de Europa ${ }^{3}$. Muchos de ellos emigraron del territorio nacional por razones políticas dirigiéndose al oeste, para salvarse de las persecuciones y con el objetivo de seguir con su actividad independentista. Ocasionalmente, la reina madre ${ }^{4}$ se encontraba con los polacos desde cuando comenzó su actividad de regenta, y luego siguió con esas prácticas siendo la eminencia gris de su hija Isabel II. Los empleaba en sus propiedades francesas (Malmaison, El Havre, Hyères, etc.) como comerciantes, sirvientes y chambelanes. Pronto las relaciones iban a adquirir un carácter familiar.

Después del comienzo de la revolución (de julio de 1854), dirigida en contra de María Cristina y los moderados que la apoyaban, los duques de Riánsares y sus hijos buscaron refugio en Francia y se establecieron, de una forma permanente, en las cercanías de París. La señora Muñoz dejó de tener cualquier influencia en la política y se dedicó a su familia. Su interés primordial era buscar maridos para sus hijas adolescentes. La causa cobraba importancia tras el intento fallido, efectuado por María Cristina, de casar a su hija mayor, María Amparo (de 20 años), con Amerigo Corsini, el hijo único del príncipe de Casigliano Andrea Corsini. Este matrimonio resultó imposible a causa de la repentina muerte del novio. Amerigo enfermó en el viaje de París (donde los jovenes se vieron por primera vez) a Florencia y murió el 13 de diciembre de $1853^{5}$.

En enero de 1855, María Cristina manda a su chambelán polaco, un tal Ratomski, al Hotel Lambert, ubicado en la isla de san Luís, que era la sede pari-

2. Tratamos a ambos juntos (aunque es María Cristina el personaje principal) porque en todos los asuntos, tanto familiares como financieros y políticos, actuaron en común.

3. Polonia había sido borrada del mapa tras las particiones efectuadas por sus vecinos: Rusia, Prusia y Austria. El último tuvo lugar en 1795. El país volvería a aparecer en el mapa de Europa después de 123 años en 1918, una vez finalizada la Gran Guerra. Durante todos estos años varias generaciones de polacos lucharon empenidarmente por recuperar la independencia.

4. El título de reina madre María Cristina lo custodiaba desde el momento de la aclamación de Isabel II como Mayor de edad (en 1843), lo que en práctica significó la toma del poder de la nueva reina de 13 años.

5. Sobre esos intentos podemos leer en la intensa correspondencia epistolar de María Cris tina con el príncipe de Casigliano, guardada en el Archivo Histórico Nacional, Diversos, Títulos y Familias (sigue la cit. AHN, D.T. y F.), 3427, leg. 187. Sin embargo, dada la mala condición de los manuscritos, no es posible analizar las cartas. El texto ecrito por la reina madre en italia no es, en gran parte, ilegible. 
sina de la aristocracia polaca y los príncipes Czartoryski, con la propuesta de casar a una de sus hijas (Ámparo o Milagros) con el príncipe Ladislao Czartoryski (de 27 años). Los padres del jóven príncipe, Adán Jorge Czartoryski y de Ana Czartoryski de soltera Sapieha, reaccionaron con un gran asombro. Pidieron conocer a las candidatas antes de ofrecer la respuesta. No obstante, la impaciente señora Muñoz no quería esperar y decidió actuar con astucia. Organizó un elegante almuerzo al que invitó a los miembros de las dos familias. Su artimaña era todavía más refinada por el hecho de haber elegido para el encuentro un terreno neutral que no fuese su casa. Para la ocasión, se sirvió de la mansión parisina de Matilde Bonaparte que pertenecía al círculo más cercano de la reina madre y que, a su vez, visitaba Malmaison ${ }^{6}$ con frecuencia.

María Czartoryska de soltera Grocholska, la cuñada de Ladislao, al describir el acontecimiento, subrayaba el pavor del príncipe momentos antes del encuentro con las hijas de la reina. A la hora acordada, la familia Czartoryski se presentó donde la princesa Matilde. Unos instantes más tarde, Ilegaron solo los duques de Riánsares, sin sus hijas, ya que las costureras no habían conseguido preparar sus vestidos a tiempo. Después de la presentación, ambas familias esperaron la llegada de las jóvenes que seguían sin aparecer. A la hora de la comida todos se sentaron a la mesa pero las doncellas aún no estaban. La comida estaba a punto de comenzar y María Cristina, nerviosa, miraba la puerta. De repente, apareció una de sus hijas, la mayor, ya que la jóven Milagros no consigió obtener su vestido. El rostro de Amparo mostraba preocupación. Desde el primer momento, su belleza y su delicadeza atrajeron a todos. El que demostró más interés fue el propio príncipe. Sintió que la princesa que tenía delante suyo le era destinada7 . ¿Cómo habría reaccionado, si también se hubiese presentado Milagros? ¿Cuál de las dos jóvenes le hubiera gustado más? La respuesta para esas preguntas nos será desconocida para siempre.

¿Por qué un polaco? No tenemos ninguna referencia en las fuentes disponibles sobre el porqué María Cristina decidió casar a una de sus hijas con Ladislao Czartoryski, tampoco sabemos cuáles eran sus motivos. Es probable que, como futuros maridos de Ámparo, le hubieran gustado otros candidatos, por ejemplo, Luís

6. En su Diario Amparo anotó algunas visitas de Matilde Bonaparte en Malmaison y las fre cuentes revisitas de María Cristina a la princesa (Biblioteca de los Príncipes Czartoryski [sigue la cit. BCz], 7358 IV, Apuntes personales de M.A. Czartoryska: desde julio hasta septiembre de 1853, Paris Malmaison).

7. Maria Ksawera od Jezusa [el nombre de María Czartoryska de soltera Grocholska, que tras la muerte de su marido Vitoldo, en 1865, ingresó en la Orden de las Carmelitas Descalzas en Posen y luego en Cracovia], Wspomnienie o ksiezznej Marii Amparo Czartoryskiej, matce sługi Bozego, Augusta Czartoryskiego, salezjanina (1858-1893), [en:] Cz. Gil OCD, Księzna w trepkach. Matka Maria Ksawera Czartoryska, karmelitanka bosa (1833-1928), Wydawnictwo Karmelitów Bosych, Kraków 2000, p. 90. 
Napoleón. Sabemos incluso que había intentado conectar con él ${ }^{8}$, como lo hizo con el príncipe Corsini. El primero de ellos, sin embargo, terminó siendo emperador y se casó con Eugenia de Montijo; el segundo, murió antes de conseguir interesarle por un posible matrimonio. Así que optó por un aristócrata polaco.

Aquí cabe subrayar que el padre de novio, Adán Jorge Czartoryski, hombre de estado, político, diplomático, escritor, mecenas, antiguo ministro de asuntos exteriores, era uno de los principales independistas polacos. Tras haber participado en el levantamiento contra Rusia (1830-1831) fue condenado por el zar Nicolás I a ser decapitado. Para salvar su vida, y la de su familia, tuvo que emigrar. Se estableció en París donde convocó un partido político conservador que tomó nombre de la sede del Hotel Lambert. Los miembros de ese partido contaron con la intervención de los países occidentales, en particular Francia e Inglaterra, en la causa polaca. Su actividad consistía principalmente en el uso de la diplomacia, apoyaban la política anti-rusa de los países europeos, los movimientos revolucionarios y nacionales.

El "Correo Universal" anotaba que María Cristina estaba muy contenta del matrimonio de Ámparo con el hijo del líder político de la emigración polaca, Adán Jorge Czartoryski. Su alegría y satisfacción eran más grandes aún porque fue ella quien había elegido el marido para su hija ${ }^{9}$. A su vez, los periódicos "Correo de Madrid" y "El Barcelonés", subrayaron la elegancia, la buena aparición, la inteligencia y la buena educación del novio ${ }^{10}$. Estas opiniones sugieren que entre las principales premisas de esa decisión se encontraban la convicción de la relevante posición de Ladislao dentro de la aristocracia parisina, la impecable opinión de la que gozaron los Czartoryski en Francia y en el exterior, y las cualidades personales del jóven. Sus raíces polacas jugaron un papel secundario. Luis José Sartorius ${ }^{11}$, que a pesar de haber recibido la invitación a la boda no pudo finalmente participar en el evento porque estaba de viaje en Roma, en su carta dirigida a Muñoz felicitó a los recién casados y añadió que el casamiento de Ámparo con un hombre de "tal nombre", que además representaba a una

8. En 1852 cuando Amparo tenía 18 años se hablaba de un posible matrimonio suyo con Luis Napoleón (Archivo de la Real Academia Española, [sigue la cit. ARAH], Archivo Narváez, caja 20/1, L.J. Sartorius a R.M. Narváez, Madrid, 13 III 1852).

9. "El Correo Universal", 15 III 1855.

10. "Correo de Madrid", 22 II 1855; "El Barcelonés", 27 II 1855.

11. Luis José Sartorius (1816 1871), moderado, ministro de la Gobernación, presidente del Consejo de Ministros, líder del grupo político Ilamado Polonia, uno de los colaboradores más cercanos a los duques de Riánsares en la década moderada (1844 1854). Durante la revolución de 1854 siguió el destino de María Cristina y su familia escapándose a Francia donde visitaba con frecuencia a los Muñoz. Pronto, sin embargo, volvió y se estableció en Madrid (biografía de Sartorius: B. Obtułowicz, Luis José Sartorius, hrabia de San Luis. "Polak", który nie był Polakiem, Wydawnictwo Naukowe Uniwersytetu Pedagogicznego w Krakowie, Kraków 2012). 
nación en lucha por su independencia, era "un extraño giro del destino"12. No se puede descartar que los Muñoz habían tenido la oportunidad de tener noticias sobre los Czartoryski ya a principios de los años cuarenta cuando, tras la adquisición de la regencia por Espartero, María Cristina visitó París. Las dos familias compartían el mismo destino de exiliados y emigrantes políticos. Además, pertenecían a los mismos ámbitos, estaban en contacto con el rey de Francia Luís Felipe I de Orleans, el tío de María Cristina, con los miembros del gobierno francés, con la élite cultural y artística de París. También es necesario saber que Ladislao, desde la mitad de los años cuarenta, mantenía corespondencia epistolar con el general Ramón María Narváez, que estaba muy cerca de la familia Muñoz ${ }^{13}$. A su vez, el hermano de Ladislao, Vitoldo Czartoryski, finalizó en los años 18451846 el servicio militar en el reconocido regimiento de "Reina Gobernadora", adquiriendo el grado de oficial. La posibilidad de ejercer la carrera en el ejército español se debía al apoyo de Narváez que, en aquella época, cumplía con la función de primer ministro. La protección era posible gracias a los esfuerzos personales de Adán Jorge Czartoryski que, aprovechando sus numerosas conexiones en las esferas de gobiernos europeos y en las cortes, intervino a través de las cartas dirgidas al Ministerio de Guerra y al propio primer ministro ${ }^{14}$.

Es significativo que a Ladislao, enamorado perdidamente de la bella española, no le importaba que su futura mujer fuera el fruto de una relación morganática, ni que sobre el romance y los negocios irregulares de sus futuros suegros se hablara en toda España y en gran parte de Europa. Ese aspecto toma relevancia si tenemos en cuenta que los jóvenes se casaron siete meses después de la Revolución de Julio de 1854. La información sobre los acentos hóstiles de la revolución hacia los Muñoz recorrió toda Europa. Lo relacionaba la prensa extranjera y, a base de esas fuentes, lo mismo hacía la prensa polaca durante las tres particiones ${ }^{15}$. Ladislao, al decidir casarse con Ámparo, no se fijaba en las opiniones negativas sobre sus futuros suegros. Únicamente, se dejaba Ilevar por un verdadero sentimiento y lo hacía decididamente, pudiendo contar con reciprocidad. Asimismo, los novios seguían el camino de María Cristina y Augustín Fernando apostando por el amor. Eso no significa que la familia Czartoryski hubiera descartado sacar provechos del matrimonio. Les impresionaba la ascen-

12. AHN, D.T. y F., 3547, leg. 11, L. J. Sartorius a A. F. Muñoz, Roma, 10 III 1855.

13. B. Obtułowicz, María Amparo Muñoz y de Borbón, księzna Czartoryska, Universitas, Kraków 2013, p. 217.

14. B. Obtułowicz, Słuzba wojskowa księcia Witolda Czartoryskiego w Hiszpanii (18451846), "Roczniki Humanistyczne. Historia”, Towarzystwo Naukowe KUL, Uniwersytet Lubels ki, t. LXII, z. 2, R. 2014, p. 91116.

15. „Czas", 3 I 1854, 3 VII 1854; "Gazeta Lwowska", 28 VIII 1854 y 4 VII 1854; "Tygodnik Petersburski”, 10/22 VIII 1854 (reimpresión de la prensa belga); „Kurier Warszawski”, 29 VI/11 VII 1854, 17/28 VII 1854. 
dencia real de la señorita Muñoz y de Borbón. Sobre todo, contaban con las buenas relaciones de Ámparo y de los duques de Riánsares con la pareja imperial francesa: Napoleón III y su mujer española Eugenia de Montijo ${ }^{16}$. Esperaban también que Ámparo, instruida por su madre, muy hábil en la diplomacia, apoyaría de una forma activa los intentos de Hotel Lambert y se convertiría en el pilar de la emigración polaca.

No disponemos de las fuentes que señalen directamente que María Cristina influía en las acciones de la hija cuando ésta se comprometía con la causa polaca. Lo que es seguro es que frecuentemente le ayudaba efectuar los encuentros con la pareja imperial durante los almuerzos, paseos y visitas en los teatros. También ocurría que, invitado por los duques de Riánsares, el emperador llegaba con su mujer a Malmaison donde todos juntos, en la mesa o durante la cabalgata en el bosque, aparte de los temas relacionados con la economía y la cultura, conversaban sobre la política. A pesar de múltiples intervenciones de Ámparo, Napoleón III mostraba su indiferencia a la causa polaca que complicaba la política exterior de Francia en Europa, en particular hacia Rusia. Por ese motivo, la joven princesa empezaba cada vez más a distanciarse de los intentos fallidos en el campo de la diplomacia de su marido, que después de la muerte de su padre, Adán Jorge, en 1861, tomó el liderazgo del partido de Hotel Lambert.

A medida de que Ámparo renunciaba gradualmente al papel de intermediaria entre Napoleón III y la dirección de Hotel Lambert, María Cristina, por su parte, mostraba cada vez más preocupación por los polacos buscando las formas de aliviar su destino. La realización de ese noble intento ayudó en el crecimiento de la exaltación contra el zar en el Reino de Polonia y, acto seguido, en el estallido de otro levantamiento antirruso en Varsovia en enero de 1863. Junto a su marido emprendió la recaudación de dinero para los insurgentes. Merece la pena mencionar que solo una de las iniciativas mencionadas anteriormente finalizó con el ingreso de casi mil francos. Los Muñoz alababan el compromiso político de su yerno y apoyaban sus misiones con sus propios fondos $^{17}$. Uno de los hermanos de Muñoz, que poseía el cuadro de Bartolomé Esteban Murillo, al enterarse de la campaña solidaria convocada por Hotel Lambert, decidió subastar la obra para regalar a los "polacos infelices"18 el dinero obtenido de la venta. En las cartas a su hija María Cristina aseguraba que si hubiera

16. Los contactos de los duques de Riánsares con la pareja imperial rondaban en torno a las finanzas (y negocios comunes) y relaciones sociales. Mientras tanto, Eugenia de Montijo era una de las amigas más cercanas de Amparo. Las dos señoras se visitaban mutuamente y man tenían correspondencia epistolar.

17. BCz, 7371 III, t. 2, A. F. Muñoz a M. A. Czartoryska, Paris, 2 II, 16 III, 4 IV 1862, Pau, 28 V 1863; BCz, 7371 III t. 1, María Cristina a M. A. Czartoryska, [Malmaison], hoy, 28 [1862].

18. BCz, 7205 II, A. F. Muñoz a L. Czartoryski, El Havre, 14 y 26 X 1863. 
tenido un ejército a mando, seguramente lo habría destinado a ayudar a los que estaban en lucha ${ }^{19}$.

Los Muñoz se solidarizaban con la misión patriótica de los príncipes Czartoryski y, al mismo tiempo, desarrollaban las relaciones familiares en común. Estas se reflejaban basicamente en las mutuas visitas realizadas con ocasión de cumpleaños, celebraciones del santo y ferias, también sin un motivo concreto ${ }^{20}$; en el intercambio de cartas $^{21}$; en ayuda recíproca y apoyo en diferentes ocasiones. María Cristina, invitando a Malmaison a los Czartoryski y sus familiares, les enviaba papeletas con información sobre el día y la hora del encuentro y las reglas en vigor ${ }^{22}$. El día más importante en el calendario de los Muñoz fue el 27 de abril, la fecha de cumpleaños de la dueña de la casa. Entonces, en el castillo de Malmaison resonaba el zumbido de voces plurilingües. De todas partes llegaban los colaboradores de los duques de Riánsares, españoles y franceses, además, aparecían los Czartoryski y los representantes de la aristocracia polaca.

Los Muñoz y los Czartoryski se juntaban también en el tiempo de ocio (equitación, esgrima, caza, etc.). El marido de la reina madre, Adán Jorge, como también Ladislao y Vitoldo, mostraba pasión por la caza. En otoño de 1860, Augustín Fernando mandó a su yerno, residiendo en la propiedad de la familia en Sieniawa (Galicia polaca), unos perros de raza. Ladis, encantado con el regalo, los probó durante su expedición para cazar los zorros. Su satisfacción por la habilidad y perspicacia de los animales se puede leer en la carta dirigida a su esposa ${ }^{23}$. Cuando los duques de Riánsares salían de París a sus residencias marítimas, siempre animaban a los miembros de la nueva familia de su hija a que les visitasen. Muñoz bromeaba que Ladis podría polaquear, es decir, ocuparse de la causa polaca no solo en París o en Londrés, sino tambíen en la costa, en El Havre y en Hyères ${ }^{24}$.

Ambas familias compartían entre si sus problemas. María Cristina y su marido lamentaban la falta de hijos de María y Vitoldo Czartoryski ${ }^{25}$. Con dolor asumie-

19. BCz, 7371 III, t. 1, María Cristina a M. A. Czartoryska, Mondesir, 9 V, 3 y 18 VIII 1863.

20. De vez en cuando los duques de Riánsares venían a Hotel Lambert de sorpresa. Lo ates tigua, entre otros, la carta de María Cristina a Amparo que estaba de visita en Neris. La madre escribe a su hija que el día anterior había visto a Ladis en Hotel Lambert, donde había apare cido sin anuncio previo, y estaba sentado en el carruaje preparado para el viaje (BCz, 7371 III, t. 1, María Cristina a M. A. Czartoryska, Paris, 29 VII 1862).

21. Correspondencia de Ladislao Czartoryski con los suegros, ejercida durante la vida de Amparo como princesa en los años 1855 1864, se encuentra en: BCz, 7373 II (con Muñoz) y BCz, 7375 II, t. 1 (con María Cristina).

22. BCz, 7371 III, t. 1, María Cristina a M. A. Czartoryska, [Malmaison, 20 I 1856]; BCz, 7373 II, María Cristina a M. A. Czartoryska, sin fecha exacta [1856].

23. BCz, 7372 III, L. Czartoryski a M. A. Czartoryski, Sieniawa, 9 IX 1860.

24. BCz, 7371 III, t.2, A. F. Muñoz a M. A. Czartoryski, [b.m.], 14 IV 1861.

25. BCz, 7373 II, A. F. Muñoz a L. Czartoryski, El Havre, 30 V 1860. 
ron también la muerte del patriarca de la familia, Adán Jorge ${ }^{26}$. De la misma menera reaccionaron los Czartoryski en respuesta a los infortunios de los Muñoz.

Una de las cosas que interrumpía una colaboración consistente entre ambas familias eran los problemas financieros. Los duques de Riánsares se mostraron generosos con los Czartoryski y la causa polaca solo a la hora de surgir el levantamiento antirruso (1863-1864). Las raíces hay que buscarlas, entre otros, en que tras la revolución de 1854, con la pérdida del poder, se les secaron las fuentes de ingresos. Todo eso coincidió con el momento de tener que afrontar múltiples gastos relacionados con la necesidad de acumular bienes para las dotes de sus hijas y la finalización de la educación de sus hijos. Los Czartoryski sufrieron de una manera visible la falta de fondos económicos al nacer su primer nieto Augusto, conocido familiarmente como Gucio, el hijo único de Ámparo y Ladis. Fue entonces cuando María Cristina les encargó, sin escrúpulos, los gastos de la canastilla para el niño ${ }^{27}$.

Vale la pena saber que la dote ofrecida a Ámparo por los duques de Riánsares no correspondía al valor de lo que se esperaba de la casa real. La cantidad era de 650 mil francos y constituía la mitad de lo que había incorporado María, la esposa de Vitoldo ${ }^{28}$. El ajuar de Ámparo consistía en los vestidos, bufandas, encajes y ropa interior por valor de 100 mil francos y las joyas valoradas en 550 mil francos. Los Muñoz se comprometieron a pagar una renta anual de 50 mil francos $^{29}$. En los documentos testamentarios de María Cristina resulta que las tres hijas (Amparo, Milagros y Cristina) recibieron dotes del mismo valor nominal. Por otro lado, es sabido que la dote de Amparo excedía a las otras porque incluía el aderezo de brillantes de un valor de 400 mil francos. Además, dado el gran valor artístico del ornamento, se puede suponer que en el pasado estaba en posesión de alguna casa real ${ }^{30}$.

El factor importante que unía a los duques de Riánsares con los Czartoryski era la figura del nieto Gucio. Amparo, de buena gana, dejaba al niño a sus padres, les mandaba sus saludos y fotografías. Una vez, incluso, ayudó a su hijo de cinco años a escribir una carta en español a sus abuelos. El texto rezaba: Queridos abuelitos, os quiero con todo mi corazón y les envío muy fuerte abrazo

26. BCz, 7371 III, t. 1, María Cristina a M. A. Czartoryska, Vichy, 17 y 21 VII 1861.

27. Biblioteca de Kórnik, 7335, C. Działyńska a G.C. Działyńska de soltera Zamoyska, París, julio de 1858.

28. J. F. Zieliński, Dziennik Hiszpański 1850-1853 [en:] Wspomnienia z tułactwa, coord. E. Wróblewska, Pax, Warszawa 1989, p. 587. Maria recibió las joyas de valor de 750 mil francos e, igual como Amparo, 50 mil de una pensión anual (J. Lenkiewiczowa, Dwie księzne Czartoryskie, Twój Styl, Warszawa, p. 15).

29. BCz, 7374 IV y 7359 III.

30. BCz, 7375 IV, t. 6., María Cristina de Borbón, Testamento. Asuntos de la herencia ("Con sulta" z 31 VII 1879). 
-August Czartorski3i. Los Muñoz llevaban al niño a Roma, El Havre y Hyères, de donde informaban a los padres de cómo Gucio se comportaba y subrayaban que era un délicieux enfant. Los abuelos cuidaban de su salud y cuando, estando en Hyères, empezó a echar los dientes, pensaron traer al médico desde París. Le obsequiaban con juguetes de valor (p. e.: los silbatos de marfil). Cuando llegaba la hora de despedirse, sentían un gran vacío y sabían que le extrañarían. El duque de Riánsares, empleando una metáfora poética, dijo en una ocasión que, después de despedirse de su nieto, se convertía en una tumba etrusca ${ }^{32}$.

Otra cuestión, esta vez un poco más molesta, que conducía a las dos familias a colaborar y apoyarse mutualmente, era la cada vez más frágil salud de Amparo, que empeoraba año tras año. Sus problemas con la salud se remontan a los tiempos de niña. Con el paso de los años su estado empeoraba, sobre todo tras parir a su hijo, y le dificultaba la vida, hasta hacerle imposible el compromiso con la causa polaca. En la correspondencia con su marido esquivaba el tema para no aumentar su preocupación. Solo cuando se sentía realmente mal, requería su presencia a su lado. Al tratar el tema de su frágil salud, se abría en particular delante de su madre. Su enfermedad fue comentada por ella misma en las cartas dirigidas a María Cristina. De allí se puede deducir cómo transcurría el malestar de la princesa. Allí es donde se queja de los resfriados, del dolor de los dientes, músculos y artritis, de hinchazones, forúnculos, conjuntivitis, gastritis, y sobre todo del malestar general: neurosis, debilidad y tos. Ésto último causaba preocupación entre los Muñoz y los Czartoryski porque síntomas parecidos, típicos de la tuberculosis, mostraban los dos hermanos de Amparo y Vitoldo Czartoryski. No es de extrañar entonces que a los duques de Riánsares no les alegraban las buenas relaciones de su hija con el hermano de Ladislao. Cuando en el verano de 1862 se fue a visitar a Vitoldo y María, que estaban en Neris, sin haberlo consultado con sus padres, ellos se inquietaron. María Cristina requirió información sobre el viaje de su hija e insistió en mantener todas las precauciones $^{33}$. Muñoz también mostraba el desacuerdo con la decisión de su hija. Advertía que no le iba a devolver la salud a Vitoldo, mientras que, en cambio, ella misma podía contraer la enfermedad. Incluso recordó un refrán español que sonaba ominoso y profético: Dios enseña: cuídate y te cuidaré, y el Espritu Santo dice: Quien ama el peligro perecerá en él. De esta manera, le aconsejaba y advertía: no juegues con tu salud! ${ }^{34}$. Los Muñoz, aunque ellos mismos no enfermaban con frecuencia, temían la tuberculosis y trataban de preve-

31. BCz, 7375 II, t. 1, M. A. Czartoryska a María Cristina, Paris, 22 IX 1863.

32. BCz, 7205 II, María Cristina a L. Czartoryski, Roma 28 IV 1861; BCz, 7371 III, t. 1, María Cristina a M.A. Czartoryska, Hyères, 31 III y 13 IV 1864; BCz, 7373 II, A.F. Muñoz a M.A. Czar toryska, hoy 4 V [sin año]; BCz, 7371 III, t. 2, H. Błotnicki, Dziennik, año de 1864.

33. BCz, 7371 III, t. 1, María Cristina a M. A. Czartoryska, Mondesir, 2 VII 1862.

34. BCz, 7371 III, t. 2, A. F. Muñoz a M. A. Czartoryska, [París], 9 VII 1862. 
nirla, desinfectando con vinagre las sillas en las que se sentaban las personas que tosían. Como si presintieran que la enfermadad, incurable en sus tiempos, en unos años les llevaría a sus tres hijos ${ }^{35}$.

Amparo estaba bajo el tratamiento de médicos de renombre que seguían los logros de la medicina en el siglo XIX, pero no mejoraba y la enfermedad avanzaba. Como el padre de Ladislao estaba muerto, su madre y el hermano Vitoldo estaban enfermos desde hacía años, la participación de los Czartoryski en la cura de la joven princesa era menor. La iniciativa y el procedimiento estaban en las manos de los duques Riánsares. Fueron ellos quienes se encargaron de buscar a nuevos médicos y consultaban los síntomas y el progreso de la enfermedad. Ana Czartoryska, por su parte, apoyaba estas prácticas y colaboraba económicamente. Además, aunque el empeño de salvar a Amparo aumentaba conforme avanzaba el deterioro de su salud, todos creían hasta el final en su recuperación. Cuando el tratamiento en los mejores centros en Francia, Suiza e Italia no dió los resultados esperados, tras las consultas con los médicos, María Cristina, desesperada, decidió llevar a su hija moribunda al campo y sanarla en las "condiciones rurales". Se trataba de colocar a la enferma en un establo, anteriormente preparado para que allí pudiese respirar sin tos ni asfixia ${ }^{36}$. No se sabe con exactitud de quién fue la idea. Es probable que lo hubiese recomendado uno de los médicos con los que los duques de Riánsares estaban en contacto. También la fecha de llevar a Amparo a ese lugar queda imprecisa. Se conoce, sin embargo, la dirección y se puede localizar el sitio. Se hallaba al final del paseo de Champs Elysées, detrás del Arco de Triunfo, en las cercanías del hipódromo y el Bosque de Boulogne. Allí estaba la mansión con jardín y el establo donde vivían doce vacas. En el centro del establo se improvisó una habitación de acolchado azul y cortinas. Al correrlas, la princesa podía ver las vacas en ambos lados ${ }^{37}$.

Desafortunadamente, tras unas semanas de estar recuperando las fuerzas en el establo, Amparo muere (19 de agosto de 1864), rodeada de los miembros de la familia Muñoz y Czartoryski.

Para María Cristina eso no significó ninguna ruptura repentina de su relación con Polonia ni con los polacos. Sus lazos con la familia Czartoryski y los compatriotas de ellos le acompañarían hasta el final de sus días. Le conmocionó la muerte de Vitoldo, fallecido un año después de Amparo en Argelia a causa de la misma enfermedad. Mantenía el contacto epistolar con su mujer María, aun cuando ella se trasladó a tierras polacas e ingresó en la orden de las carmelitas ${ }^{38}$. Todavía más

35. Maria Ksawera od Jesusa, op. cit., p. 91.

36. BCz, 7220 III, A. F. Muñoz a L. Czartoryski, El Havre, 8 VI 1864.

37. Maria Ksawera od Jezusa, op. cit., s. 91; J. Lenkiewiczowa, op. cit., p. 35.

38. BCz, 7206 II, María Cristina a L. Czartoryski, Somio, 16 XI 1865; ibidem, A. F. Muñoz a L. Czartoryski, El Havre, 19 y 29 XI 1865; AHN, D.T. y F., 3466, leg. 330, M. Czartoryska de soltera Grocholska a María Cristina, Posen, 6 III 1874. 
cerca estaba con Ladislao, el padre de su querido nieto Augusto y un político activo, el líder de Hotel Lambert. Junto con su marido le mostraba pruebas de gratitud, calidez familiar, respeto y solidaridad con la causa polaca. Los Muñoz se encontraban con el antiguo yerno, le enviaban cartas, se interesaban por su salud, el traspaso de su misión patriótica, el destino de la pauvre Pologne y por la situación de la familia. María Cristina se dirigía al príncipe de la misma manera como lo hacía antes: Mon cher fils, y firmaba las cartas: Votre Mère ${ }^{39}$.

Los duques de Riánsares no tenían nada en contra del nuevo matrimonio de Ladislao, en esta ocasión con la princesa Margarita de Orleans (en 1872), la nieta de Luis Felipe I de Orleans. Entendían perfectamente que, para actuar con éxito en el campo de su labor patriótica, necesitaba ayuda y apoyo por parte de una mujer que le amara. Sabían también que siendo débil de salud Gucio para asegurar la sucesión de la familia, deseaba poder contar con más hijos. La aceptación de su nueva prometida era todavía más fácil por ser ella, a través de Luis Felipe I, la prima hermana de Amparo. María Cristina pronto congenió con la nueva familia (polaco-francesa) de Ladis y empezó la correspondencia epistolar con su nueva mujer y su hijo mayor Adán Luis; también les invitaba a sus residencias francesas. En los contactos con María, la viuda de Vitoldo, alababa a notre excellent Ladis, Marguerite, Auguste et tout la famille Czartoryskit ${ }^{40}$.

Ladislao, agradecido por esa actitud, respondía de la misma manera. Sobre todo, permanecía en contacto con sus antiguos suegros a través de las visitas y una correspondencia regular. En sus cartas les informaba en particular sobre su nieto preferido, su salud y progresos en educación. También prestaba la atención a que el nieto escribiera cartas a sus abuelos. Al mismo tiempo, no descuidaba el contacto con las hermanas de Amparo interesándose por su salud y quehaceres familiares ${ }^{41}$.

María Cristina sentía un afecto especial hacia Augusto. A pesar de tener muchos deberes políticos, económicos y sociales, encontraba el tiempo para sus nietos, cada vez más numerosos. Merece la pena subrayar que dentro de ese grupo, Gucio tenía un papel especial. En primer lugar, porque era semi-huérfano, el hijo de su querida hija. También, porque vivía, igual que los Muñoz, en Francia, lo que facilitaba los contactos personales. Los duques de Riánsares no intervenían en la formación ni educación del nieto dejándolo a su padre, pero sí estaban al día con el estado de su salud, seguían su desarrollo físico e inte-

39. Cartas de los duques de Riánsares con Ladislao Czartoryski: AHN, D.T. y F., 3564, leg. 28, 3566, leg. 30; BCz, 7207 II, 7209 III, 7246 III.

40. AHN, D.T. y F., 3566, leg. 330, María Cristina a M. Czartoryska de soltera Grocholska, Paris Passy, 15 III 1874. Cartas de María Cristina y de su esposo con Margarita de Orleans: AHN, D.T. y F., 3463, leg. 317; BCz, 7210 II.

41. Cartas de Ladislao Czartoryski con los duques de Riánsares y con las hermanas de Amparo: BCz, 7206 II. 
lectual. Le llevaban consigo a sus propiedades de Normandía y Costa Azul, visitaban Hotel Lambert, se acordaban de sus cumpleaños, le daban regalos, durante el tiempo sin verle, le escribían cartas, pedían que se les mandara las fotografías actuales. Las cartas de María Cristina a Augusto se caracterizan por su tono muy cálido y equilibrado. Siendo madre y abuela, teniendo una gran experiencia en el campo de la política, sabía influir de una manera diplomática en su nieto y enseñarle a respetar a su padre y a los miembros, cercanos y lejanos, de ambas familias.

El tutor de Augusto, Hipólito Błotnicki, anotó en una carta a Ladislao que durante la visita que los dos hicieron a la reina madre en París en mayo de 1866, fueron acogidos con amabilidad aunque también con distancia, un poco fría como para abuela. Se notaba que era difícil ser la reina y la abuela al mismo tiem$p o^{42}$. En realidad, María Cristina sabía compaginar las dos funciones y también como abuela cumplía con su papel perfectamente. El pequeño Augusto lo hubiera admitido sin ninguna duda, ya que se sentía muy a gusto al lado de sus abuelos españoles. Disfrutaba de cada ocasión cuando pasaba el tiempo con ellos. Los domingos desayunaba y comía con ellos. Con el paso de los años, al crecer, progresar en sus estudios y adquirir el conocimiento sobre el mundo, sus relaciones con María Cristina y su marido seguían siendo cálidas, de mutua preocupación y comprensión. Los Muñoz le compensaban la pérdida prematura de su madre y le transmitían seguridad. Además, le ofrecían la posibilidad de diversión sin preocupaciones y descanso, y le enseñaban como mirar con confianza hacia el futuro incierto. Les alegraban sus múltiples intereses y preocupaciones y le aconsejaban la moderación en todo. Apenas a los once años Augusto ya sabía montar a caballo, con lo que impresionó a su abuelo, gran amante de los cabaIlos y dueño de una caballeriza ${ }^{43}$, y con lo que atormentó a su abuela. Viendo a su nieto montando a caballo, le prevenía contra la bravuconería, repitiendo a gritos: ¡cuidado!, ¡cuidado! Gucio sabía también nadar y patinaba en invierno. Empezaba a descubrir la magia de teatro, la pintura y la música. En una ocasión, al pasar un rato en Hotel Lambert, en una hora los duques de Riánsares pudieron escuchar cómo su nieto tocaba el piano. Impresionados con el talento del niño, le advirtieron a Francisco Lutrzykowski, otro tutor suyo, que el niño no debía comenzar con las clases de canto aun, ya que todavía era demasiado joven y no tenía la voz y forzaría la garganta y el pecho ${ }^{44}$. El comentario tenía sus fundamen-

42. BCz, 7208 II, H. Błotnicki a L. Czartoryski, París, 28 IV 1867.

43. C. Cambronero, Crónicas del tiempo de Isabel II, La España Moderna, Madrid, 1913, p. 162 163. Sobre la caballería del duque de Riánsares vea también: AHN, D.T. y F., 3402, leg. 119, Estado de las Reales Caballerízas del Señor Duque de Riánsares, 1846.

44. BCz, 7194 II, F. Lutrzykowski a L. Czartoryski, París, 23 V 1869. Sobre las impresiones de los Muñoz con el talento musical de Gucio: BCz, 7209 II, A. F. Muñoz a L. Czartoryski, El Havre, 21 VI 1869. 
tos. María Cristina poseía experiencia en criar y educar a sus propios hijos. Cabe mencionar que en Madrid había fundado el primer conservatorio en España donde, a expensas del Estado, estudiaban más de trescientos jóvenes, chicas y chicos. Además, ella tenía talento musical, tocaba el piano, cantaba y antes del año 1854, es decir, antes de emigrar a Francia de forma permanente, ofrecía conciertos públicos en los escenarios de los teatros en Madrid ${ }^{45}$.

En verano de 1873, después de pasar el examen del latín en el Liceo de Carlomagno en París, Augusto fue invitado por la abuela a su casa en Sainte-Adresse, cerca de El Havre. El joven tenía la intención de explorar los barcos transatlánticos que, en aquella época, le apasionaban, recoger conchas, bañarse en el mar. La abuela intenta convencerme para ir a América. Así que, estoy preparando el viaje, aunque es un proyecto todavía. Tal vez, cuando vaya, tendré la oportunidad de ver Niagara, Ohio, Mississipi, las sabanas, los búfalos salvajes, porque hay barcos que recorren Mississipi, Ohio y pasan cerca de Niagara $^{46}$-escribía a su padre esperando poder confirmar pronto lo que había aprendido de América con sus profesores particulares y los del liceo-. El proyecto, sin embargo, no se realizó. Como compensación, al volver a París, subió al tren con la maleta llena de regalos de sus abuelos, entre los cuales se encontraban los libros de viaje, naturaleza, historia y ciencia ${ }^{47}$.

La unión entre María Cristina y su nieto se puede comprobar también en la carta que Augusto dirige a su abuela al prepararse a la primera comunión que, a causa del estallido de la guerra franco-prusiana y la Comuna de París, se iba a celebrar en París y no en Sieniawa, es decir, en el territorio del Imperio austrohúngaro. Dio a entender que en un momento tan importante considera a su abuela como la representante de su madre ${ }^{48}$. En realidad, María Cristina ya cumplía este papel, incluso cuando Ladislao se casó de nuevo con Margarita que, por su parte, le trataba a Gucio muy bien. En la correspondencia con su nieto, como seguramente lo hacía también en persona, mencionaba a Amparo ${ }^{49}$. Además, siempre cuidaba de su salud y seguridad, en particular cuando a causa de la guerra surgió el peligro de que Austria pudiera romper su neutralidad e implicarse en el conflicto ${ }^{50}$.

María Cristina se convirtió en alguien especialmente importante para él tras la muerte de su abuelo en Sainte-Adresse, en septiembre de 1873. En aquella

45. C. A. González, Música de su niñez: 1830 1843, en: Isabel II. Los espejos de la reina, ed. J. S. Pérez Garzón, Tauron, Madrid 2004, pp. 215216.

46. BCz, 7195 II A. Czartoryski a L. Czartoryski, Paris 25 VII 1873.

47. BCz, 7210 II, T. Grocholski a L. Czartoryski, [Paris], VIII 1873.

48. AHN, D.T. y F., 3461, leg. 305, A. Czartoryski a María Cristina, París, 18 XIII 1869.

49. Ibidem, María Cristina a A. Czartoryski, Hyères, 7 I 1870.

50. Ibidem, María Cristina a L. Czartoryski, El Havre, 5 VIII 1870. 
época, Gucio continuaba sus estudios en el Liceo Carlomagno de París y, al mismo tiempo, ejercía viajes educativos y terapéuticos.

En el Archivo Histórico Nacional en Madrid se guardan extensas cartas de Augusto dirigidas a María Cristina, donde con detalles describía sus impresiones de los viajes por Francia, Inglaterra, Suiza y las tierras polacas ${ }^{51}$. Las cartas atestiguan la estrecha relación entre la abuela y su nieto. La lectura de esas cartas le suministraba a María Cristina las informaciones sobre el progreso intelectual y emocional de su nieto, pero también por éstas se enteraba de las nuevas formas de actividad patriótica de los Czartoryski, que después de la pérdida de Francia en la guerra franco-prusiana y tras la caída de Napoleón III, dejaron la lucha diplomática por Polonia para, en cambio, tratar de mantener el sentido de la identidad nacional de los polacos. Gucio escribía, entre otros, sobre el compromiso de Ladislao con la creación del Museo y la Biblioteca de Czartoryski en Cracovia. Mencionaba la compra de su padre del edificio del arsenal de la ciudad y el intento de juntar en él los libros y las obras de arte acumuladas por varias generaciones de la familia ${ }^{52}$. Vale la pena mencionar que entre los cuadros poseídos, se encontraba la obra de Leonardo Da Vinci La Dama del Armiño, adquirida en 1800 por el suegro de Amparo, Adán Jorge Czartoryski en el Piamonte. Actualmente, el cuadro aún pertenece a la colección del Museo de los Príncipes Czartoryski en Cracovia. En 2011, por primera vez el cuadro fue exhibido en España durante la exposición organizada en el Palacio Real de Madrid, titulada: Polonia. Tesoros y colecciones artísticas ${ }^{53}$.

Entre un viaje y otro, al estar en París Augusto pasaba muchas horas con su abuela: desayunaba con ella y escuchaba las misas celebradas por el cura polaco José Kalinowski ${ }^{54}$. Incluso, aun cuando pasaba cortas temporadas junto con su madrastra y hermanos en Neuilly, cerca de París, cada día emprendía el viaje en un carruaje, atravesando el Bosque de Boulogne, a la capital para ver a María Cristina que tras el fallecimiento de su marido se sentía cada vez más sola ${ }^{55}$. En verano de 1877, a causa del calor en París, Augusto se fue a Normandía (Trouville y El Havre), desde donde acudía a la mansión de los Muñoz en SainteAdresse, donde veraneaba su abuela. En estas ocasiones le informaba a su padre que la mansión, grande y cómoda, se iba deteriorando por estar deshabitada y daba una "impresión triste" ${ }^{\prime 56}$. También María Cristina, por su parte, visitaba el

51. AHN, D.T. y F., 3465, leg. 323, A. Czartoryski a María Cristina, Inverneis, 20 VII 1874, Menton, 21 III 1875, Eaux Bonnes, 9 VII 1874, Gołuchów, 23 IX 1875.

52. AHN, D.T. y F., 3465, leg. 323, A. Czartoryski a María Cristina, Gołuchów, 23 IX 1875.

53. B. Obtułowicz, La familia Czartoryski y sus vínculos con España con La Dama del Armiño en el fondo, "Estudios Hispanicos", XXI (Contraste y periferia): Uniwersytet Wrocławski, Wrocław 2013, p. 145158.

54. BCz, 7195 II, A. Czartoryski a L. Czartoryski, París, 15 VI y 8 VIII 1874.

55. Ibidem, A. Czartoryski a L. Czartoryski, Neuilly, 16, 22, 30 V 1875.

56. BCz, 7196 II, A. Czartoryski a L. Czartoryski, El Havre (hotel Frascati), 26 VI 1877. 
Hotel Frascati en El Havre, donde se hospedaba Augusto. Al encontrarse allí, pasaban largas horas conversando y la abuela le dejaba recados para Ladislao ${ }^{57}$.

Sin embargo, el dichoso tiempo de mutuos encuentros llegó a su fin cuando Augusto se fue a Davos y María Cristina perdía cada vez más la salud ${ }^{58}$. En enero de 1878, se sentía bien y deseaba mandarle a su nieto un regalo de Año Nuevo. Pidió a Ladislao que le aconsejara algo que le fuera agradable a Gucio ${ }^{59}$. En julio, Augusto veraneaba en Normandía junto con su familia polaca y María Cristina estaba en Neuilly, bajo la supervisión de los médicos, pero su estado de salud no era satisfactorio ${ }^{60}$. Pronto iría a Sainte-Adresse para descansar. Allí, no obstante, sufrió una recaída y murió el 23 de agosto, rodeada de sus hijas y nietos que la visitaban y acompañaban a lo largo de su enfermedad ${ }^{61}$.

Como la única de la familia, María Cristina Muñoz y de Borbón intentó despertar en su nieto el interés por España. Augusto, aunque naciera en París, fue educado en el espíritu polaco, por la total entrega de la familia Czartoryski a la causa polaca. Asimismo, su identidad había sido definida de antemano. María Cristina, sin embargo, se esforzó en que también sintiera el vínculo con la patria de su madre. Por eso, le convencía de que estudiara español, justificándolo de la siguiente manera: no quiero que olvides la lengua de tu Madre, en que tantas veces nos dijimos ella y yo nuestro cariño ${ }^{62}$. Para facilitarle el aprendizaje, algunas de las cartas las escribía en este idioma, a pesar de que su lengua de comunicación diara fue el francés. Al mismo tiempo, le invitaba a que visitara España donde vivía su tía Cristina (hermana de Amparo). Incluso le regaló cuatro volúmenes de Le voyage de l'Espagne ${ }^{63}$, que consideraba un repertorio de la historia del país.

Resumiendo, los contactos de María Cristina con los polacos al principio eran casuales y a corto plazo. Les daba empleo, sin fijarse demasiado en su procedencia, en sus mansiones francesas donde desempeñaban diferentes papeles. En la Europa del siglo XIX, como hoy en día, convivían representantes de múltiples nacionalidades y esas prácticas no eran nada extrañas. Al mismo tiempo, mantenía relaciones oficiales, de negocios y sociales con las élites europeas. Entre los últimos se encontraban los Czartoryski. A partir de la boda de Amparo con Ladislao, las relaciones de reina madre con los polacos cobraron contun-

57. Ibidem, A. Czartoryski a L. Czartoryski, El Havre, 3 VII 1877.

58. Ibidem, Davos, 14, 23 XII 1877.

59. Ibidem, Davos, 9 । 1878.

60. Ibidem, Trouville, 5 VII 1878; BCz, 7535 III, L. Czartoryski a A. Czartoryski, París, 24 V 1878.

61. F. Jiménez, M. Salcedo, Augusto Czartoryski. Príncipe de Polonia-Duque de Vista Alegre. Sobrino de Isabel II de España, Editorial CCS, Madrid 2004, p. 30.

62. AHN, D.T. y F., 3461, leg. 305, María Cristina a A. Czartoryski, Hyères, 7 I 1870.

63. AHN, D.T. y F., 3469, leg. 340, A. Czartoryski a María Cristina, Menton, 6 II 1876. 
dencia, se volvieron constantes, muy cercanos, hasta amistosos, como resultado del carácter entrañable de ambas familias. Frente a la familia polaca de su hija, María Cristina tomó una postura muy leal, lo que no era fácil dada la complicación de la misión independentista realizada por ellos. La causa polaca le era, a pesar de todo, bastante lejana. Como ex-reina y la eminencia gris de Isabel II, no encontraba ningun interés en el asunto pero, pese a eso, comprendía la situación en que se encontraba la familia Czartoryski y sus compatriotas. Participaba con ganas en la actividad diplomática de Hotel Lambert. Su compromiso y entrega eran notables, hasta tal punto que, cuando Amparo buscaba excusas para prescindir de mediación entre la pareja imperial francesa y Hotel Lambert, le convencía de que mantuviera la perserverancia y el sacrificio. No sin menor determinación, apoyaba a los insurgentes polacos (que participaban en el levantamiento antirruso en 1863).

Las fuentes analizadas atestiguan que María Cristina no solo sabía ser buena esposa y madre, sino también era un miembro más de la familia polaca, útil y comprometida. El matrimonio de sus dos hijas con los extranjeros (Milagros se había casado con el príncipe romano del Drago) revelaron la empatía y compresión de la duquesa de Riánsares ante los representantes de otras nacionalidades. El matrimonio, premeditado por ella misma, de Amparo con un aristócrata polaco, confirma una verdad, cuestionada con frecuencia, que María Cristina, que tras la revolución de 1854 fue apodada de "ladrona", tenía también su "lado humano". 